\title{
Clinical Profile of Persons with Multiple Sclerosis Across the Continuum of Care
}

\author{
Luke A. Turcotte, Ruth Ann Marrie, Scott B. Patten, John P. Hirdes
}

\begin{abstract}
Background: This study is part of the Innovations in Data, Evidence and Applications for Persons with Neurological Conditions project to understand the strengths, preferences, and needs of persons with neurological conditions living in Canada. Objective: To estimate the prevalence and describe the sociodemographic and clinical characteristics of persons with multiple sclerosis in Canadian home care, nursing home, Complex Continuing Care hospitals, and inpatient mental health care settings. Methods: Cross-sectional study of adults aged 18 years and older with multiple sclerosis (MS; $\mathrm{n}=11,250)$ across Canada from 1996 through 2011 using interRAI Resident Assessment Instrument (RAI) comprehensive health assessments (RAI Minimum Data Set 2.0, RAI-Home Care, RAI-Mental Health). Comparisons were made to adults with Alzheimer's disease and related dementias $(\mathrm{n}=260,910)$, other neurological conditions $(n=163,578)$ and non-neurological conditions $(n=571,567)$. Results: The prevalence of MS was highest in Complex Continuing Care hospitals (4125 cases per 100,000 patients), followed by home care (2020 cases per 100,000 patients), nursing homes (1424 cases per 100,000 patients), and mental health settings (138 cases per 100,000 patients). Persons with MS experienced greater impairment in the completion of activities of daily living, pain, pressure ulcers, swallowing difficulty, depression, and anxiety compared with peers within care settings. There were also significant differences between settings, particularly the degree of physical and cognitive impairment experienced by persons with MS. Conclusions: Except for mental health care settings, the prevalence of MS in community, institutional and hospitalbased care settings exceeded that of the general population. These data describing the sociodemographic and clinical characteristics of persons with MS may be used to inform clinical practice and policy decisions for persons with MS across the continuum of care.
\end{abstract}

RÉSUMÉ: Profil clinique des personnes atteintes de sclérose en plaques à travers la gamme complète des soins. Contexte: Cette étude fait partie du projet Innovations in Data, Evidence and Applications for Persons with Neurological Conditions dont le but est de comprendre les forces, les préférences et les besoins des personnes atteintes de maladies neurologiques vivant au Canada. Objectif: Le but de cette étude était d'estimer la prévalence et de décrire les caractéristiques sociodémographiques et cliniques des personnes atteintes de sclérose en plaques (SP) vivant à domicile, dans des résidences pour malades chroniques, des hôpitaux offrant des soins continus complexes et des institutions pour personnes atteintes de problèmes mentaux. Méthodologie: Nous avons effectué une étude transversale portant sur des adultes âgés de 18 ans et plus, qui étaient atteints de SP $(\mathrm{n}=11$ 250) à travers le Canada entre 1996 et 2011. Nous avons utilisé les InterRAI Resident Assessment Instrument (RAI) Comprehensive Health Assessments (RAI Minimum Data Set 2.0, RAI-Home Care, RAI-Mental Health). Nous avons comparé les adultes atteints de SP à des adultes atteints de la maladie d'Alzheimer et d'affections connexes ( $\mathrm{n}=260$ 910), d'autres maladies neurologiques ( $\mathrm{n}=163$ 578) et de maladies autres que neurologiques $(\mathrm{n}=571567)$. Résultats: C'est dans les hôpitaux offrant des soins continus complexes que la prévalence de la SP était la plus élevée (4 125 cas par 100000 patients), suivie de celle des patients recevant des soins à domicile (2 020 cas par 100000 patients), des patients vivant en résidence pour malades chroniques (1 424 cas par 100000 patients) et en institution pour personnes atteintes de problèmes mentaux (138 cas par 100000 patients). Les personnes atteintes de SP présentaient des contraintes plus sévères dans l'exécution des activités de la vie quotidienne, plus de douleur, d'escarres, de dysphagie, de dépression et d'anxiété par rapport à des pairs vivant dans un milieu où des soins leur étaient fournis. Il y avait également des différences significatives entre les différents milieux, particulièrement en ce qui a trait au degré de handicap physique et cognitif présent chez les patients. Conclusions: La prévalence de la SP dans la communauté, les établissements et les hôpitaux était supérieure à celle de la population en général. Mis à part les établissements de soins de santé mentale, ces données décrivant les caractéristiques sociodémographiques et cliniques des personnes atteintes de la SP peuvent être utilisées pour éclairer la pratique clinique et les décisions politiques concernant toute la gamme de soins que nécessitent les personnes atteintes de la SP.

Key words: Multiple Sclerosis, Nervous System Diseases, Long-Term Care, Nursing Home, Home Care, interRAI doi:10.1017/cjn.2017.274

Can J Neurol Sci. 2018; 45: 188-198

Multiple sclerosis (MS) is a progressively disabling disease of the central nervous system. Symptoms may include impaired vision, weakness, ataxia, fatigue, bowel and bladder dysfunction, and cognitive impairment, among other symptoms. ${ }^{1}$ Given the physical and cognitive impairments associated with MS, longterm care services may be needed to assist individuals with MS in

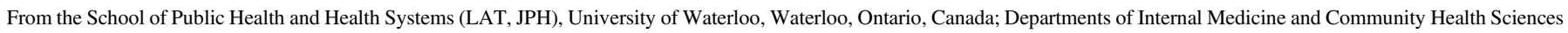

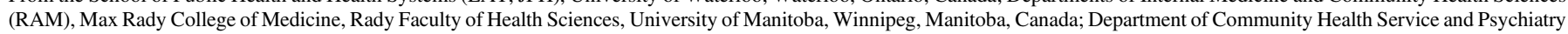
(SBP), University of Calgary, Calgary, Alberta, Canada

Received June 14, 2016. Revised September 6, 2017. Date of Acceptance September 19, 2017.

Correspondence to: Luke A. Turcotte, School of Public Health and Health Systems, University of Waterloo, 200 University Avenue West, Waterloo, ON N2L 3G1.

Email: luke.turcotte@uwaterloo.ca 
maintaining their physical and mental well-being. Long-term care refers to a continuum of services that may be delivered in community (e.g. home care, day programs) or institutional (e.g. nursing home care) settings. 2,3

In the United States, several studies have evaluated the clinical and demographic characteristics of persons with MS admitted to Medicare- and Medicaid-certified nursing homes. ${ }^{4-6}$ Compared with other nursing home residents, persons with MS were younger at admission and more physically disabled, but less cognitively impaired. ${ }^{4}$ Depression was common at admission and it increased substantially in the year after admission, yet most persons with MS did not receive mental health services. ${ }^{5,6}$ These findings raise questions about the quality of care for persons with MS in these settings, both in the availability of mental health services and providers' capacity to respond to the psychosocial needs of this patient population. Further, it is uncertain how persons with MS who receive care in institutional settings may differ from those who receive long-term care services in the community, a question of importance to patients, their families, and policy makers.

In Canada, interRAI Resident Assessment Instrument (RAI) assessments are used as part of routine clinical practice in home care, nursing home, Complex Continuing Care (CCC) hospitals, and inpatient psychiatry. Data from these assessments populate the Continuing Care Reporting System, Ontario Association of Community Care Access Centres Home Care Database, and the Ontario Mental Health Reporting System. ${ }^{7-10}$ The interRAI assessment system includes a suite of comprehensive clinical assessments that are compatible across health care settings to collect person-level data in domains such as physical functioning, cognition, mood and behavior, social functioning, disease and health conditions, health service, and medication utilization. ${ }^{11-13}$ Widespread implementation of interRAI assessments in Canada ${ }^{7,8}$ provides an opportunity to compare the clinical characteristics of persons with MS across multiple care settings. Substantial international adoption of interRAI assessments also permits national comparisons of clinical features and care provision for persons with MS. ${ }^{13}$

The Innovations in Data, Evidence and Applications for Persons with Neurological Conditions project was conducted to estimate the cross-sector prevalence, clinical characteristics, and needs of persons with eleven neurological conditions living in
Canada. The present study provides prevalence estimates and a clinical profile of individuals affected by MS across four care settings: inpatient mental health, home care, nursing home, and CCC hospitals.

\section{METHODS}

\section{Data Sources}

\section{Continuing Care Reporting System}

Nursing homes and CCC hospitals in nine Canadian provinces and territories have implemented the RAI Minimum Data Set (RAI-MDS 2.0) or its successor the interRAI Long Term Care Facility assessment (being implemented in New Brunswick). All individuals with a length of stay of 14 days or longer are assessed with the RAI-MDS 2.0, providing near census-level health information on individuals within these care settings. Implementation dates differ by province, and two (Alberta and New Brunswick) had not begun to submit data to the Canadian Institute of Health Information at the time of this study. The nursing home cohort comprises the most recent assessments for unique individuals completed from July 1, 2003, to March 31, 2011, in Ontario and Nova Scotia; July 1, 2006, to March 31, 2011, in British Columbia; and July 1, 2008, to March 1, 2011, in Manitoba (Winnipeg Regional Health Authority only, accounting for $60 \%$ of the Manitoba population), Newfoundland, Saskatchewan, and Yukon Territory (Table 1). CCCs provide hospital-based longterm complex medical care, geriatric assessment and rehabilitation, psycho-geriatric care, palliative care, and respite care. ${ }^{14}$ They are differentiated from nursing homes in Ontario based on their delivery of care to medically complex patients as opposed to frail persons with stable medical conditions. ${ }^{7}$ The CCC cohort includes the most recent assessments from April 10, 1996, to March 31, 2011, in Ontario, and from July 1, 2008, to March 31, 2011, in Manitoba (Table 1).

\section{Ontario Association of Community Care Access Centres Home Care Database}

Individuals who are expected to use home care services provided by one of Ontario's 14 Community Care Access Centres

Table 1: Assessment period coverage by care setting cohort and Canadian province/territory

\begin{tabular}{|c|c|c|c|c|}
\hline Province/territory & Mental health & Home care & Nursing home & $\begin{array}{c}\text { Complex Continuing } \\
\text { Care }\end{array}$ \\
\hline Ontario & $\begin{array}{c}1 / 10 / 2005-3 / 31 / 2010 \\
(\mathrm{n}=114,158)\end{array}$ & $\begin{array}{c}1 / 1 / 2002-12 / 31 / 2010 \\
(n=520,455)\end{array}$ & $\begin{array}{c}7 / 1 / 2003-3 / 31 / 2011 \\
(\mathrm{n}=135,245)\end{array}$ & $\begin{array}{c}4 / 10 / 1996-3 / 31 / 2011 \\
(\mathrm{n}=181,846)\end{array}$ \\
\hline Nova Scotia & & & $\begin{array}{c}7 / 1 / 2003-3 / 31 / 2011 \\
(\mathrm{n}=1674)\end{array}$ & \\
\hline British Columbia & & & $\begin{array}{c}7 / 1 / 2006-3 / 31 / 2011 \\
(\mathrm{n}=135,245)\end{array}$ & \\
\hline $\begin{array}{l}\text { Manitoba (Winnipeg Regional } \\
\text { Health Authority) }\end{array}$ & & & $\begin{array}{c}7 / 1 / 2008-3 / 31 / 2011 \\
(\mathrm{n}=9409)\end{array}$ & $\begin{array}{c}7 / 1 / 2008-3 / 31 / 2011 \\
(\mathrm{n}=298)\end{array}$ \\
\hline Newfoundland & & & $\begin{array}{c}7 / 1 / 2008-3 / 31 / 2011 \\
(\mathrm{n}=712)\end{array}$ & \\
\hline Saskatchewan & & & $\begin{array}{c}07 / 01 / 2008-3 / 31 / 2011 \\
(\mathrm{n}=27,067)\end{array}$ & \\
\hline Yukon Territory & & & $\begin{array}{c}7 / 1 / 2008-3 / 31 / 2011 \\
(\mathrm{n}=248)\end{array}$ & \\
\hline
\end{tabular}


for 60 days or longer, representing one-third of clients, are evaluated using the RAI-Home Care (RAI-HC). ${ }^{15}$ The home care cohort includes the most recent assessments for unique individuals from January 1, 2002, to December 31, 2010 (Table 1). Although RAI-HC data are available for other provinces, only the Ontario data were used because it was the only province to include home care data on all neurological conditions of interest for the larger project for which this study was conducted.

\section{Ontario Mental Health Reporting System}

All Ontario inpatient mental health patients across 55 hospitals and 13 specialty psychiatric facilities are assessed using the RAIMental Health (RAI-MH). ${ }^{16}$ The mental health cohort includes the most recent admission assessments for unique individuals hospitalized from October 1, 2005, to March 21, 2010 (Table 1).

\section{Clinical Scales and Items}

The RAI-MDS 2.0, RAI-HC, and RAI-MH instruments share a common set of items and validated clinical scales to assess patients across a broad range of health domains, including physical functioning, cognition, mood and behavior, social functioning, diseases and conditions, health service, and medication utilization. $^{11,13}$ The Cognitive Performance Scale (CPS) is a measure of cognitive impairment that ranges from 0 (intact) to 6 (very severely impaired). ${ }^{17-19}$ The Depression Rating Scale (DRS) is a depression screening instrument derived from seven mood items. The DRS ranges from 0 to 14 ; scores of 3 or greater indicate depressive disorders. ${ }^{20}$ The Activities of Daily Living Hierarchy Scale is a measure of functional performance that ranges from 0 (no impairment) to 6 (total dependence) based upon the ability to complete early and late loss activities of daily living (ADLs). ${ }^{21}$ The pain scale ranges from 0 (no pain) to 3 (excruciating pain) and is a highly predictive of visual analog scale pain scores. ${ }^{22}$ Finally, the Changes in Health, End-Stage Disease, Signs and Symptoms Scale is a measure of health instability that is predictive of mortality and ranges from 0 (no health instability) to 5 (very high health instability). ${ }^{23.24}$

Despite substantial overlap across interRAI instruments, it is important to note that the RAI-MH differs from the RAI-MDS 2.0 and RAI-HC instruments in its collection of information on appetite, pressure ulcers, and psychotropic drug use. For this reason, results on these items are not presented for patients in the mental health cohort.

\section{Identification of Persons with MS}

Persons with an MS diagnosis were identified based on pick list item responses on the RAI-MDS 2.0, RAI-HC, and free-text International Statistical Classification of Diseases and Related Health Problems, Tenth Revision, Canada (ICD-10-CA) fields on the RAI-MH instrument. Clinicians are instructed to complete these assessments using all sources of information available. Although most information may be obtained through patient interview and observation, medical records (i.e. physician orders, laboratory data, medication records, and care plans), family members, and the attending physician may also be consulted to complete the assessment. Previous work has established the validity of these methods for identifying persons with an MS diagnosis compared with diagnoses listed on administrative hospital records. ${ }^{25,26}$ Instruments relying on pick list responses achieved very high sensitivity (90\%-94\%), specificity (99\%$100 \%)$, and interrater agreement $($ kappa $=0.76-0.84) .{ }^{25}$ The RAI-MH, which relies on ICD-10-CA code responses, also performed well with a sensitivity of $77 \%$, specificity of $100 \%$, and kappa of $0.61 .^{25}$ MS prevalence estimates in Canada using the entire history of patient administrative health records were found to be comparable to estimates based RAI MDS 2.0, RAI-HC, and RAI-MH index assessments alone. ${ }^{27}$

\section{Comparison Groups}

Four groups were identified for comparison in this study: MS; Alzheimer's disease and related dementias (ADRD); other neurological conditions; and non-neurological conditions. The ADRD group comprised individuals identified with an ADRD diagnosis using the pick list and ICD-10-CA methods previously detailed for those with MS. The other neurological conditions group included individuals identified using interRAI assessments as having a diagnosis of one or more priority conditions included in the Public Health Agency of Canada's National Population Health Study of Neurological Conditions, except ADRD. ${ }^{28}$ These diagnoses were Parkinson's disease, epilepsy, traumatic brain injury, Huntington's disease, spinal cord injury, amyotrophic lateral sclerosis, muscular dystrophy, cerebral palsy, and stroke. ${ }^{29}$

Finally, individuals without a diagnosis of MS, ADRD, or any of the previously forementioned neurological conditions formed the non-neurological condition comparison group. Note that several conditions including congenital neurological deficit, neuropathy, migraine, tension headache, and other neurological conditions are not included in interRAI assessments, so individuals with these conditions may appear in any of the four study groups. With the exception of the non-neurological conditions group, group assignment was not mutually exclusive. Individuals with comorbid neurological conditions, including MS and ADRD, may appear in multiple groups. Table 2 details the composition of the other neurological conditions comparison group.

Table 2: Composition of the other neurological conditions comparison group across care setting cohorts

\begin{tabular}{l|c|c|c|c}
\hline Condition & $\begin{array}{c}\text { Mental } \\
\text { health } \\
(\mathbf{n = 1 6 2 7})\end{array}$ & $\begin{array}{c}\text { Home care } \\
(\mathbf{n = 8 8 , 5 8 3 )}\end{array}$ & $\begin{array}{c}\text { Nursing } \\
\text { home } \\
(\mathbf{n = 2 9 , 6 1 9 )}\end{array}$ & $\begin{array}{c}\text { Complex } \\
\text { Continuing Care } \\
(\mathbf{n = 4 3 , 7 4 9 )}\end{array}$ \\
\hline Stroke, \% & 11.7 & 74.3 & 69.8 & 70.7 \\
\hline Epilepsy, \% & 46.8 & 5.2 & 15.0 & 15.8 \\
\hline $\begin{array}{c}\text { Parkinson's } \\
\text { disease, \% }\end{array}$ & 20.4 & 15.5 & 17.3 & 11.1 \\
\hline TBI, \% & 8.7 & 5.5 & 3.6 & 4.9 \\
\hline CP, \% & 8.2 & 2.2 & 3.1 & 1.5 \\
\hline SCI, \% & 0.4 & 0.3 & 3.5 & 8.2 \\
\hline $\begin{array}{c}\text { Huntington's } \\
\text { disease, \% }\end{array}$ & 4.4 & 0.5 & 1.0 & 0.3 \\
\hline ALS, \% & 0.6 & 1.6 & 0.6 & 0.8 \\
\hline MD, \% & 1.8 & 0.8 & 0.2 & 0.3 \\
\hline
\end{tabular}

$\mathrm{ALS}=$ amyotrophic lateral sclerosis $\mathrm{CP}=$ cerebral palsy; $\mathrm{MD}=$ muscular dystrophy; $\mathrm{SCI}=$ spinal cord injury; $\mathrm{TBI}=$ traumatic brain injury. 


\section{Analysis}

Demographic and clinical characteristics of persons with MS, ADRD, other neurological conditions, and non-neurological conditions were compared within and across care setting using items and scales in the RAI-MDS 2.0, RAI-HC, and RAI-MH instruments. Chi-square tests were performed both between groups within each of the four care setting cohorts and within groups between the four care setting cohorts to ascertain the statistical significance of group and setting frequency differences. Given the large number of statistical tests performed, a Bonferroni correction was made. ${ }^{30}$ This yielded an adjusted alpha of $0.05 / 105=0.0005$ per test. In part because of the large sample sizes used in this study, only demographic and clinical characteristic comparisons that were significant to an alpha level of 0.0001 were reported. In all care settings, the most recent assessment for each individual was included in the sample used to calculate group demographic and clinical characteristics.

To estimate the point prevalence of MS in each of the four care settings, a prevalence sample comprising Ontario patients receiving care in one of the four care settings on July 1, 2009 (index date) was created. This index date was selected because there was complete interRAI assessment coverage across the four care settings in Ontario at that time. For patients in nursing homes, CCC hospitals, and mental health settings, facility admission and all-cause discharge dates were used to determine inclusion in the prevalence sample. Home care patients in Ontario may remain on service for long periods without actively receiving home care services (e.g. home health aide or nursing visits). To restrict the prevalence sample to patients actively receiving home care services, only patients with a home care referral date before the index date and a RAI-HC assessment completed 180 days before or after the index date were included. Where all-cause discharge dates were available for home care patients, this information was also used to determine inclusion in the secondary sample. The number of individuals included in the denominator for each of the care settings was 110,123 in home care, 68,060 in nursing homes, 4945 in CCC hospitals, and 4360 in mental health settings.

All analyses were conducted using SAS, version 9.2, SAS Institute Inc., Cary, NC.

\section{ReSUlts}

Across the four care setting cohorts, 11,250 persons with MS were identified. In Ontario, among patients receiving care on July 1, 2009, MS was most prevalent in CCC hospitals (4125 cases per 100,000 patients (95\% confidence interval [CI], 3596-4727), followed by home care (2020 cases per 100,000 patients [95\% CI, $1939-2106])$, nursing homes (1424 cases per 100,000 patients [95\% CI, 1337-1516]), and mental health settings (138 cases per 100,000 patients [95\% CI, 56-316]). In all four care settings, persons with MS were predominantly female and were younger than other persons in these settings (Table 3 ).

\section{Clinical Measures and Scales}

Rates of moderate to severe cognitive impairment (CPS 3+) were higher in institutional settings than in the community. Fewer persons with MS in the home care and mental health cohorts had moderate to severe cognitive impairment compared with $39.6 \%$ in nursing homes and $42.3 \%$ in CCC hospitals (Table 4). Within all four care settings, persons with MS were less likely to have moderate to severe cognitive impairment (CPS 3+) compared with the ADRD and other neurological conditions comparison groups; however, their rates were consistently higher than in the non-neurological comparison group (Table 4).

Persons with MS in the nursing home and CCC cohorts were less independent in completing ADLs compared with those with MS in the home care and mental health cohorts. The percentage of patients with moderate to severe ADL impairment (Activities of Daily Living Hierarchy Scale $3+$ ) was $13.1 \%$ of the mental health cohort and $38.8 \%$ of the home care cohort compared with $91.2 \%$ of the nursing home cohort and $89.4 \%$ of the CCC cohort (Table 4). Except for in mental health settings, persons with MS were more likely to be moderate to severely functionally impaired compared with the non-neurological conditions, ADRD, and other neurological conditions comparison groups in each setting (Table 4).

\section{Mobility and Falls}

Except in the mental health cohort, persons with MS were more likely to use a wheelchair than the ADRD, non-neurological conditions, and other neurological conditions comparison groups (Table 5). Irrespective of method of ambulation, $38.1 \%$ of persons with MS in home care fell in the 90 days before assessment. Fall assessment time frames differ on the RAI-MDS 2.0 and RAI-HC assessment. In the mental health cohort, $17.9 \%$ of persons with MS experienced a fall in the 30 days before assessment compared with $10.0 \%$ in $\mathrm{CCC}$ and $6.4 \%$ in nursing homes (Table 5). Within the mental health and home care setting cohorts, the rate of falls by persons with MS was similar to the ADRD and other neurological conditions comparison groups. However, within the nursing home and CCC cohorts, where they were likely to be wheelchair users, persons with MS were least likely of all groups to have experienced a recent fall (Table 5).

\section{Mental Health Issues and Psychotropic Drug and Restraint Use}

Across care settings, persons with MS were most likely to show signs of depression (DRS 3+) in the mental health $(62.4 \%)$, nursing home $(28.9 \%)$, and CCC $(24.6 \%)$ care settings (Table 6). Within settings, persons with MS were generally more likely to show signs of depression compared with the other neurological conditions comparison group, but less likely to show signs of depression compared with the ADRD group (Table 6).

In the mental health cohort, $59.0 \%$ of persons with MS displayed anxiety symptoms compared with $12.9 \%$ in home care, $33.4 \%$ in nursing home, and $25.7 \%$ in CCC (Table 6). In the nursing home cohort, $28.7 \%$ of persons with MS displayed aggressive behaviors compared with $25.3 \%$ in mental health, $21.8 \%$ in CCC, and $4.2 \%$ in home care. Within all settings, persons with MS were less likely to have aggressive behaviors compared with the ADRD and other neurological conditions comparison groups (Table 6).

Except for the non-neurological conditions comparison group in the home care cohort, within care settings, persons with MS were least likely of all groups to be prescribed antipsychotic medications (Table 6). Conversely, within settings, persons with 
Table 3: Sociodemographic profile of persons with in the MS, ADRD, non-neurological and other neurological conditions comparison groups

\begin{tabular}{|c|c|c|c|c|c|c|c|c|}
\hline & \multicolumn{4}{|c|}{ Mental health } & \multicolumn{4}{|c|}{ Home care } \\
\hline & $\begin{array}{l}\text { Non-neurological } \\
\text { conditions }\end{array}$ & ADRD & $\begin{array}{c}\text { Other } \\
\text { neurological } \\
\text { conditions }\end{array}$ & MS & $\begin{array}{c}\text { Non- } \\
\text { neurological } \\
\text { conditions }\end{array}$ & ADRD & $\begin{array}{c}\text { Other } \\
\text { neurological } \\
\text { conditions }\end{array}$ & MS \\
\hline $\mathbf{n}$ & 104,648 & 7667 & 1627 & 229 & 320,581 & 105,343 & 88,583 & 6163 \\
\hline Female & $48.8 \%(51,112)$ & $48.6 \%(3728)$ & $44.4 \%(722)$ & $71.6 \%(164)$ & $64.7 \%(207,546)$ & $63.6 \%(67,027)$ & $56.2 \%(49,753)$ & $70.9 \%(4,370)$ \\
\hline \multicolumn{9}{|c|}{ Age group } \\
\hline $0-44$ & $57.0 \%(59,645)$ & $6.9 \%(532)$ & $39.7 \%(646)$ & $40.2 \%(92)$ & $4.9 \%(15,585)$ & $0.3 \%(308)$ & $4.1 \%(3632)$ & $14.9 \%$ (919) \\
\hline $45-54$ & $22.7 \%(23,786)$ & $6.2 \%(479)$ & $22.1 \%(359)$ & $33.2 \%(76)$ & $6.6 \%(21,125)$ & $0.5 \%(536)$ & $4.6 \%(4056)$ & $25.4 \%(1566)$ \\
\hline $55-64$ & $12.1 \%(12,682)$ & $11.3 \%(865)$ & $17.6 \%(286)$ & $20.5 \%(47)$ & $11.1 \%(35,430)$ & $2.1 \%(2209)$ & $8.9 \%(7922)$ & $28.0 \%(1727)$ \\
\hline $65-74$ & $5.1 \%(5333)$ & $22.4 \%(1719)$ & $12.5 \%(204)$ & $5.7 \%(13)$ & $16.6 \%(53,113)$ & $10.0 \%(10,566)$ & $17.5 \%(15,494)$ & $18.5 \%(1138)$ \\
\hline $75-84$ & $2.5 \%(2593)$ & $36.4 \%$ (2794) & $6.3 \%(103)$ & $0.4 \%(1)$ & $31.6 \%(101,379)$ & $43.6 \%(45,930)$ & $36.6 \%(32,291)$ & $10.7 \%(657)$ \\
\hline \multirow[t]{3}{*}{$85+$} & $0.6 \%(608)$ & $16.7 \%(1278)$ & $1.8 \%(29)$ & $0 \%(0)$ & $29.3 \%(93,877)$ & $43.4 \%(45,725)$ & $28.3 \%(25,068)$ & $2.5 \%(156)$ \\
\hline & \multicolumn{4}{|c|}{ Nursing home } & \multicolumn{4}{|c|}{ Complex Continuing Care } \\
\hline & $\begin{array}{l}\text { Non-neurological } \\
\text { conditions }\end{array}$ & ADRD & $\begin{array}{l}\text { Other neurolo- } \\
\text { gical } \\
\text { conditions }\end{array}$ & MS & $\begin{array}{c}\text { Non- } \\
\text { neurological } \\
\text { conditions }\end{array}$ & ADRD & $\begin{array}{l}\text { Other neurolo- } \\
\text { gical } \\
\text { conditions }\end{array}$ & MS \\
\hline $\mathbf{n}$ & 51,000 & 107,381 & 29,619 & 2430 & $\mathbf{9 5 , 3 3 8}$ & 40,519 & 43,749 & 2428 \\
\hline Female & $69.5 \%(35,462)$ & $68.8 \%(73,901)$ & $58.5 \%(17,306)$ & $68.9 \%(1,674)$ & $61.0 \%(58,135)$ & $56.2 \%(22,755)$ & $51.4 \%(22,466)$ & $65.3 \%(1,585)$ \\
\hline \multicolumn{9}{|c|}{ Age group } \\
\hline $0-44$ & $0.7 \%(369)$ & $0.1 \%(107)$ & $2.0 \%(579)$ & $4.7 \%(115)$ & $2.0 \%(1860)$ & $0.5 \%(188)$ & $4.2 \%(1817)$ & $12.9 \%(312)$ \\
\hline $45-54$ & $1.6 \%(826)$ & $0.4 \%(420)$ & $3.5 \%(1029)$ & $17.6 \%(428)$ & $3.9 \%(3690)$ & $1.1 \%(444)$ & $5.2 \%(2266)$ & $22.4 \%(544)$ \\
\hline $55-64$ & $4.4 \%(2262)$ & $1.7 \%(1789)$ & $7.5 \%(2,229)$ & $27.0 \%(656)$ & $8.7 \%(8246)$ & $3.1 \%(1246)$ & $10.0 \%(4355)$ & $24.6 \%(598)$ \\
\hline $65-74$ & $9.3 \%(4716)$ & $6.5 \%(6944)$ & $13.8 \%(4085)$ & $23.9 \%(580)$ & $19.4 \%(18,433)$ & $11.9 \%(4812)$ & $21.6 \%(9429)$ & $22.3 \%(541)$ \\
\hline 75-84 & $26.5 \%(13,488)$ & $31.0 \%(33,226)$ & $31.9 \%(9432)$ & $18.4 \%(446)$ & $36.7 \%(34,993)$ & $41.5 \%(16,778)$ & $36.9 \%(16,148)$ & $14.3 \%(348)$ \\
\hline $85+$ & $57.5 \%(29,316)$ & $60.4 \%(64,860)$ & $41.4 \%(12,251)$ & $8.4 \%(203)$ & $29.4 \%(28,026)$ & $42.0 \%(17,008)$ & $22.2 \%$ (9699) & $3.4 \%(83)$ \\
\hline
\end{tabular}

Unless otherwise noted, the chi-square p values for group comparisons performed within and across settings are less than 0.0001 .

MS were most likely of all groups to be prescribed antidepressant medications. The same was true for anxiolytic and sedative medications, except in the CCC cohort (Table 6).

Care by a social worker or psychologist was infrequently provided outside of the mental health setting. Only persons with MS in the home care cohort were more likely than other groups to have contact with a social worker or psychologist on one or more occasions in the past 7 days (Table 6).

In the nursing home and CCC cohorts, a similar proportion of persons with MS were restrained with a mechanical restraint or chair that prevents rising in the 7 days preceding assessment (26.5\% and $25.3 \%$, respectively; Table 6 ). These rates are similar for the ADRD group in these two settings; however, in mental health only, $6.6 \%$ of persons with MS were restrained in the 3 days preceding assessment compared with $24.1 \%$ in the ADRD group (Table 6).

\section{Discussion}

This cross-sectional study establishes disease prevalence estimates and clinical profiles for persons with MS across the Canadian continuum of care. Using ADRD, other neurological conditions, and non-neurological conditions comparison groups, this study also differentiates persons with MS from other individuals within each of the care settings.

Several recent systematic reviews have summarized the epidemiological literature reporting the prevalence of MS among the general population in the North and South America, ${ }^{31}$ Europe $^{32}$ Africa, and Asia-Pacific ${ }^{33}$ regions. The current study aimed to estimate the prevalence of MS among individuals receiving care in community, institutional, and hospital-based care settings. Given that admission to these care settings is largely dependent on demonstrated need for formal care as a result of disability or illness, it is expected that the prevalence of MS in these care settings would be greater than among the general population. The prevalence of MS in the home care, nursing home, and CCC care settings in this study was approximately 7 to 21 times greater than in the Canadian general population, which ranges between 195 and 298 cases per 100,000 patients. $^{34-38}$ The prevalence of MS among individuals in the mental health cohort was similar to that of the general population, likely because this care setting is oriented toward caring for patients with psychiatric conditions rather than physical disabilities. It has also been hypothesized that mental health 
Table 4: Clinical scale distributions for persons in the MS, ADRD, non-neurological, and other neurological conditions comparison groups

\begin{tabular}{|c|c|c|c|c|c|c|c|c|}
\hline & \multicolumn{4}{|c|}{ Mental health } & \multicolumn{4}{|c|}{ Home care } \\
\hline & $\begin{array}{c}\text { Non- } \\
\text { neurological } \\
\text { conditions }\end{array}$ & ADRD & $\begin{array}{c}\text { Other } \\
\text { neurological } \\
\text { conditions }\end{array}$ & MS & $\begin{array}{c}\text { Non- } \\
\text { neurological } \\
\text { conditions }\end{array}$ & ADRD & $\begin{array}{c}\text { Other } \\
\text { neurological } \\
\text { conditions }\end{array}$ & MS \\
\hline $\mathbf{n}$ & 104,648 & 7667 & 1627 & 229 & 320,581 & 105,343 & 88,583 & 6163 \\
\hline \multicolumn{9}{|l|}{ CPS } \\
\hline 0 & $67.6 \%(70,754)$ & $11.5 \%(880)$ & $46.7 \%(759)$ & $59.0 \%(135)$ & $63.5 \%(20,3707)$ & $1.6 \%(1,684)$ & $38.8 \%(34,352)$ & $52.6 \%(3,241)$ \\
\hline $1-2$ & $26.4 \%(27,582)$ & $33.7 \%(2587)$ & $37.7 \%(613)$ & $33.2 \%(76)$ & $33.1 \%(10,6104)$ & $50.4 \%(53,087)$ & $51.0 \%(45,176)$ & $40.5 \%(2493)$ \\
\hline $3-4$ & $4.2 \%(4393)$ & $25.6 \%(1962)$ & $9.1 \%(148)$ & $5.2 \%(12)$ & $2.4 \%(7559)$ & $29.3 \%(30,849)$ & $6.7 \%(5919)$ & $4.1 \%(252)$ \\
\hline $5-6$ & $1.8 \%(1919)$ & $29.2 \%(2238)$ & $6.6 \%(107)$ & $2.6 \%(6)$ & $1.0 \%(3192)$ & $18.7 \%(19,718)$ & $3.5 \%(3132)$ & $2.9 \%(177)$ \\
\hline \multicolumn{9}{|c|}{ ADL Hierarchy Scale } \\
\hline 0 & $87.5 \%(91,537)$ & $34.0 \%(2605)$ & $67.8 \%(1103)$ & $68.1 \%(156)$ & $73.1 \%(23,4164)$ & $37.2 \%(39,139)$ & $54.0 \%(47,789)$ & $44.3 \%(2729)$ \\
\hline $1-2$ & $9.0 \%(9432)$ & $23.8 \%(1822)$ & $17.0 \%(276)$ & $18.8 \%(43)$ & $18.1 \%(58,089)$ & $37.9 \%(39,923)$ & $25.7 \%(22,719)$ & $16.9 \%(1043)$ \\
\hline $3+$ & $3.5 \%(3679)$ & $42.3 \%(3240)$ & $15.2 \%(248)$ & $13.1 \%(30)$ & $8.8 \%(28,277)$ & $24.9 \%(26,269)$ & $20.4 \%(18,064)$ & $38.8 \%(2390)$ \\
\hline \multicolumn{9}{|c|}{ Pain scale } \\
\hline 0 & $77.5 \%(81,102)$ & $72.1 \%(5526)$ & $72.2 \%(1175)$ & $55.9 \%(128)$ & $29.7 \%(95,338)$ & $53.8 \%(56,622)$ & $36.3 \%(32,191)$ & $35.4 \%(2181)$ \\
\hline $1-2$ & $20.0 \%(20,907)$ & $25.2 \%(1931)$ & $24.5 \%(398)$ & $34.5 \%(79)$ & $54.7 \%(175,198)$ & $41.5 \%(43,734)$ & $51.5 \%(45,584)$ & $49.0 \%(3017)$ \\
\hline $3+$ & $2.5 \%(2,639)$ & $2.7 \%(210)$ & $3.3 \%(54)$ & $9.6 \%(22)$ & $15.6 \%(49,985)$ & $4.7 \%(4,974)$ & $12.2 \%(10,800)$ & $15.7 \%(965)$ \\
\hline \multicolumn{9}{|c|}{ CHESS scale } \\
\hline 0 & $61.8 \%(64,664)$ & $39.0 \%(2991)$ & $56.5 \%(919)$ & $54.1 \%(124)$ & $31.2 \%(99,960)$ & $25.6 \%(26,950)$ & $32.2 \%(28,505)$ & $37.3 \%(2297)$ \\
\hline $1-2$ & $33.9 \%(35,436)$ & $47.3 \%(3628)$ & $37.1 \%(603)$ & $38.0 \%(87)$ & $54.4 \%(174,422)$ & $58.4 \%(61,486)$ & $54.8 \%(48,577)$ & $55.3 \%(3407)$ \\
\hline \multirow[t]{3}{*}{$3+$} & $4.3 \%(4548)$ & $13.7 \%(1048)$ & $6.5 \%(105)$ & $7.9 \%(18)$ & $14.4 \%(46,160)$ & $16.0 \%(16,903)$ & $13 \%(11,495)$ & $7.4 \%(459)$ \\
\hline & \multicolumn{4}{|c|}{ Nursing home } & \multicolumn{4}{|c|}{ Complex Continuing Care } \\
\hline & $\begin{array}{c}\text { Non- } \\
\text { neurological } \\
\text { conditions }\end{array}$ & ADRD & $\begin{array}{c}\text { Other neuro- } \\
\text { logical } \\
\text { conditions }\end{array}$ & MS & $\begin{array}{c}\text { Non- } \\
\text { neurological } \\
\text { conditions }\end{array}$ & ADRD & $\begin{array}{l}\text { Other neuro- } \\
\text { logical } \\
\text { conditions }\end{array}$ & MS \\
\hline $\mathbf{n}$ & 51,000 & 107,381 & 29,619 & 2430 & $\mathbf{9 5 , 3 3 8}$ & 40,519 & 43,749 & 2428 \\
\hline \multicolumn{9}{|l|}{ CPS } \\
\hline 0 & $32.6 \%(16,607)$ & $2.3 \%(2,439)$ & $19.7 \%(5,829)$ & $29.4 \%(714)$ & $34.3 \%(32,748)$ & $2.2 \%(879)$ & $17.5 \%(7,676)$ & $30.4 \%(737)$ \\
\hline $1-2$ & $35.6 \%(18,162)$ & $16.1 \%(17,293)$ & $34.0 \%(10,075)$ & $31.0 \%(754)$ & $35.2 \%(33,532)$ & $16.1 \%(6531)$ & $30.9 \%(13,497)$ & $27.3 \%(663)$ \\
\hline $3-4$ & $22.2 \%(11,311)$ & $41.8 \%(44,873)$ & $31.1 \%(9210)$ & $25.3 \%(614)$ & $20.3 \%(19,346)$ & $39.5 \%(16,009)$ & $28.2 \%(12,317)$ & $22.0 \%(534)$ \\
\hline $5-6$ & $9.6 \%(4920)$ & $39.8 \%(42,776)$ & $15.2 \%(4505)$ & $14.3 \%(348)$ & $10.2 \%(9712)$ & $42.2 \%(17,100)$ & $23.4 \%(10,259)$ & $20.3 \%(494)$ \\
\hline \multicolumn{9}{|c|}{ ADL Hierarchy Scale } \\
\hline 0 & $11.9 \%(6083)$ & $3.2 \%(3480)$ & $5.6 \%(1650)$ & $2.8 \%(68)$ & $8.5 \%(8146)$ & $3.3 \%(1332)$ & $4.3 \%(1902)$ & $2.9 \%(71)$ \\
\hline $1-2$ & $23.7 \%(12,065)$ & $13.8 \%(14,823)$ & $13.9 \%(4122)$ & $6.0 \%(146)$ & $24.9 \%(23,695)$ & $17.5 \%(7072)$ & $17.3 \%(7590)$ & $7.7 \%(187)$ \\
\hline $3+$ & $64.4 \%(32,852)$ & $83.0 \%(89,078)$ & $80.5 \%(23,847)$ & $91.2 \%(2216)$ & $66.6 \%(63,497)$ & $79.3 \%(32,115)$ & $78.3 \%(34,257)$ & $89.4 \%(2170)$ \\
\hline \multicolumn{9}{|c|}{ Pain scale } \\
\hline 0 & $41.7 \%(21,282)$ & $57.9 \%(62,145)$ & $48.1 \%(14,237)$ & $49.3 \%(1199)$ & $20.6 \%(19,629)$ & $35.7 \%(14,467)$ & $32.2 \%(14,087)$ & $33.5 \%(813)$ \\
\hline $1-2$ & $52.3 \%(26,662)$ & $39.3 \%(42,186)$ & $47.4 \%(14,035)$ & $45.7 \%(1111)$ & $66.7 \%(63,585)$ & $58.0 \%(23,497)$ & $59.6 \%(26,088)$ & $56.4 \%(1368)$ \\
\hline $3+$ & $6.0 \%(3,056)$ & $2.8 \%(3,050)$ & $4.5 \%(1,346)$ & $4.9 \%(120)$ & $12.7 \%(12,110)$ & $6.3 \%(2,548)$ & $8.1 \%(3,562)$ & $10.1 \%(245)$ \\
\hline \multicolumn{9}{|c|}{ CHESS scale } \\
\hline 0 & $39 \%(18,106)$ & $37.9 \%(37,485)$ & $42.7 \%(11,468)$ & $48.3 \%(1038)$ & $15.8 \%(13,914)$ & $17.0 \%(6658)$ & $22.9 \%(8607)$ & $34.4 \%(680)$ \\
\hline $1-2$ & $47.1 \%(21,876)$ & $48.1 \%(47,513)$ & $45.3 \%(12,165)$ & $43.9 \%(943)$ & $42.1 \%(37,071)$ & $43.2 \%(16,864)$ & $45.8 \%(17,240)$ & $46.6 \%(922)$ \\
\hline $3+$ & $14.0 \%$ (6494) & $14.0 \%(13,803)$ & $12.0 \%(3227)$ & $7.8 \%(168)$ & $42.1 \%(37,111)$ & $39.8 \%(15,534)$ & $31.4 \%(11,811)$ & $19.0 \%(376)$ \\
\hline
\end{tabular}

Unless otherwise noted, the chi-square $\mathrm{p}$ values for group comparisons performed within and across settings are less than 0.0001 .

CHESS $=$ Changes in Health, End-Stage Disease, Signs and Symptoms Scale; CPS = Cognitive Performance Scale. 
Table 5: Health and social profile persons with in the MS, ADRD, non-neurological, and other neurological conditions comparison groups

\begin{tabular}{|c|c|c|c|c|c|c|c|c|}
\hline & \multicolumn{4}{|c|}{ Mental health } & \multicolumn{4}{|c|}{ Home care } \\
\hline & $\begin{array}{c}\text { Non- } \\
\text { neurological } \\
\text { conditions }\end{array}$ & ADRD & $\begin{array}{c}\text { Other } \\
\text { neurological } \\
\text { conditions }\end{array}$ & MS & $\begin{array}{c}\text { Non- } \\
\text { neurological } \\
\text { conditions }\end{array}$ & ADRD & $\begin{array}{l}\text { Other } \\
\text { neurological } \\
\text { conditions }\end{array}$ & MS \\
\hline $\mathbf{n}$ & 104,648 & 7667 & 1627 & 229 & 320,581 & 105,343 & 88,583 & 6163 \\
\hline \multicolumn{9}{|l|}{ Health issues } \\
\hline $\begin{array}{l}\text { Shortness of } \\
\text { breath }\end{array}$ & $3.7 \%(3887)$ & $6.5 \%(501)$ & $4.4 \%(72)$ & $5.7 \%(13)$ & $28.0 \%(89,703)$ & $14.9 \%(15,687)$ & $24.7 \%(21,916)$ & $11.5 \%$ (708) \\
\hline Loss of appetite* & - & - & - & - & $12.8 \%(41,181)$ & $7.4 \%(7761)$ & $\begin{array}{r}8.8 \% \\
(7831)\end{array}$ & $7.0 \%(430)$ \\
\hline Pressure ulcers* & - & - & - & - & $9.0 \%(28,733)$ & $5.0 \%(5262)$ & $7.8 \%(6876)$ & $13.1 \%(806)$ \\
\hline $\begin{array}{l}\text { Trouble } \\
\text { swallowing }\end{array}$ & $2.3 \%(2428)$ & $8.2 \%(632)$ & $8.2 \%(133)$ & $9.2 \%(21)$ & $6.5 \%(20,740)$ & $10.2 \%(10,761)$ & $14.7 \%(13,054)$ & $17.7 \%(1088)$ \\
\hline \multicolumn{9}{|l|}{$\begin{array}{l}\text { Occasional or worse } \\
\text { incontinence }\end{array}$} \\
\hline Bladder & $1.6 \%(1655)$ & $27.5 \%(2110)$ & $8.3 \%(135)$ & $10.0 \%(23)$ & $20.2 \%(64,748)$ & $44.8 \%(47,175)$ & $32.8 \%(29,065)$ & $37.4 \%$ (2305) \\
\hline Bowel & $0.9 \%(933)$ & $19.5 \%(1493)$ & $5.1 \%(83)$ & $4.8 \%(11)$ & $6.1 \%(19,594)$ & $21.5 \%(22,628)$ & $11.9 \%(10,520)$ & $20.7 \%$ (1274) \\
\hline \multicolumn{9}{|l|}{ Mobility } \\
\hline Uses wheelchair & $18.1 \%(18,941)$ & $29.9 \%(2290)$ & $25.7 \%(418)$ & $29.3 \%(67)$ & $6.8 \%(21,934)$ & $8.4 \%(8901)$ & $16.3 \%(14,453)$ & $48.0 \%(2958)$ \\
\hline \multirow[t]{3}{*}{ Recent fall $\|$} & $5.0 \%(5236)$ & $17.0 \%(1304)$ & $14.1 \%(230)$ & $17.9 \%(41)$ & $28.8 \%(92,446)$ & $35.1 \%(36,998)$ & $38.4 \%(34,000)$ & $38.1 \%(2350)$ \\
\hline & \multicolumn{4}{|c|}{ Nursing home } & \multicolumn{4}{|c|}{ Complex Continuing Care } \\
\hline & $\begin{array}{c}\text { Non- } \\
\text { neurological } \\
\text { conditions }\end{array}$ & ADRD & $\begin{array}{l}\text { Other neuro- } \\
\text { logical } \\
\text { conditions }\end{array}$ & MS & $\begin{array}{c}\text { Non- } \\
\text { neurological } \\
\text { conditions }\end{array}$ & ADRD & $\begin{array}{l}\text { Other neurolo- } \\
\text { gical conditions }\end{array}$ & MS \\
\hline $\mathbf{n}$ & 51,000 & 107,381 & 29,619 & 2430 & 95,338 & 40,519 & 43,749 & 2428 \\
\hline \multicolumn{9}{|l|}{ Health issues } \\
\hline $\begin{array}{l}\text { Shortness of } \\
\text { breath }\end{array}$ & $18.3 \%(9355)$ & $9.9 \%(10,653)$ & $12.9 \%(3812)$ & $6.7 \%(164)$ & $32.9 \%(31,367)$ & $22.4 \%(9092)$ & $21.6 \%(9436)$ & $16.4 \%(398)$ \\
\hline Loss of appetite* & $29.2 \%(13,568)$ & $36.3 \%(35,898)$ & $28.6 \%(7695)$ & $25.6 \%(550)$ & $39.1 \%(34,476)$ & $40.8 \%(15,953)$ & $30.8 \%(11,601)$ & $26.8 \%(531)$ \\
\hline Pressure ulcers* & $8.3 \%(4220)$ & $7.3 \%(7802)$ & $8.5 \%(2517)$ & $13.8 \%(335)$ & $14.5 \%(13,852)$ & $15.4 \%(6245)$ & $14.3 \%(6239)$ & $19.5 \%(473)$ \\
\hline $\begin{array}{l}\text { Trouble } \\
\text { swallowing }\end{array}$ & $13.0 \%(6636)$ & $24.9 \%(26,690)$ & $28.8 \%(8535)$ & $34.2 \%(830)$ & $18.6 \%(17,762)$ & $31.3 \%(12,666)$ & $40.9 \%(17,911)$ & $43.5 \%(1055)$ \\
\hline \multicolumn{9}{|l|}{$\begin{array}{l}\text { Occasional or worse } \\
\text { incontinence }\end{array}$} \\
\hline Bladder & $53.9 \%(27,494)$ & $79.3 \%(85,205)$ & $68.3 \%(20,219)$ & $63.6 \%(1546)$ & $32.9 \%(31,329)$ & $59.9 \%(24,283)$ & $49.8 \%(21,771)$ & $45.1 \%(1094)$ \\
\hline Bowel & $26.9 \%(13,703)$ & $53.9 \%(57,840)$ & $41.3 \%(12,239)$ & $58.2 \%(1415)$ & $27.4 \%(26,082)$ & $49.8 \%(20,161)$ & $46.0 \%(20,139)$ & $62.6 \%(1520)$ \\
\hline \multicolumn{9}{|l|}{ Mobility } \\
\hline Uses wheelchair & $56.7 \%(14,784) \dagger$ & $59.4 \%(29,300) \ddagger$ & $70.9 \%(9966) \S$ & $85.4 \%(901)$ पा & $44.7 \%(35,705) \dagger$ & $52.0 \%(16,738) \ddagger$ & $58.3 \%(18,100) \S$ & $71.6 \%(971) \mathrm{d}$ \\
\hline Recent fall $\|$ & $14.8 \%$ (7554) & $16.2 \%(17,449)$ & $13.5 \%$ (4007) & $6.4 \%(155)$ & $24.5 \%(23,394)$ & $28.6 \%(11,593)$ & $19.7 \%(8600)$ & $10.0 \%(242)$ \\
\hline
\end{tabular}

Unless otherwise noted, the chi-square p values for group comparisons performed within and across settings are less than 0.0001

*Items not available on RAI-MH assessment.

$\dagger$ Uses wheelchair item for patients in the non-neurological conditions group measured on 26,074 NH assessments and 79,965 CCC assessments.

†Uses wheelchair item for patients in the ADRD group measured on 49,368 NH assessments and 32,189 CCC assessments.

$\S$ Uses wheelchair item for patients in the other neurological conditions group measured on 14,058 NH assessments and 31,021 CCC assessments.

IUUses wheelchair item for patients in the MS group measured on $1055 \mathrm{NH}$ assessments and $1356 \mathrm{CCC}$ assessments.

॥Fell in past 30 days in $\mathrm{MH} / \mathrm{CCC} / \mathrm{NH}$; fell in past 90 days in $\mathrm{HC}$.

facilities may not have the capacity to attend to the medical complexity of persons with $\mathrm{MS},{ }^{27}$ thereby reducing access to psychiatric care for persons with MS who are more likely to have comorbid mental health conditions. ${ }^{39}$
The results of this study illustrate that MS is a complex neurological condition that affects domains of health and wellbeing beyond physical and cognitive impairment. Most notable are mental health issues such as depression and anxiety. 
Table 6: Mental health, behavior, and psychotropic drug use profile of persons with in the MS, ADRD, non-neurological, and other neurological conditions comparison groups

\begin{tabular}{|c|c|c|c|c|c|c|c|c|}
\hline & \multicolumn{4}{|c|}{ Mental health } & \multicolumn{4}{|c|}{ Home care } \\
\hline & $\begin{array}{c}\text { Non- } \\
\text { neurological } \\
\text { conditions }\end{array}$ & ADRD & $\begin{array}{c}\text { Other } \\
\text { neurological } \\
\text { conditions }\end{array}$ & MS & $\begin{array}{c}\text { Non- } \\
\text { neurological } \\
\text { conditions }\end{array}$ & ADRD & $\begin{array}{c}\text { Other } \\
\text { neurological } \\
\text { conditions }\end{array}$ & MS \\
\hline $\mathbf{n}$ & 104,648 & 7667 & 1627 & 229 & 320,581 & 105,343 & 88,583 & 6163 \\
\hline \multicolumn{9}{|l|}{ DRS } \\
\hline 0 & $18.0 \%(18,840)$ & $20.5 \%(1,569)$ & $17.0 \%(277)$ & $13.5 \%(31)$ & $63.6 \%(203,665)$ & $53.0 \%(55,819)$ & $60.1 \%(53,210)$ & $59.9 \%(3689)$ \\
\hline $1-2$ & $30.9 \%(32,297)$ & $31.7 \%(2430)$ & $29.6 \%(482)$ & $24,0 \%(55)$ & $22.0 \%(70,452)$ & $27.1 \%(28,515)$ & $24.0 \%(21,275)$ & $22.8 \%(1407)$ \\
\hline $3+$ & $51.1 \%(53,511)$ & $47.8 \%(3668)$ & $53.3 \%(868)$ & $62.4 \%(143)$ & $14.5 \%(46,346)$ & $19.9 \%(20,979)$ & $15.9 \%(14,068)$ & $17.3 \%(1063)$ \\
\hline Anxiety symptoms & $50.7 \%(53,034)$ & $46.5 \%(3565)$ & $54.7 \%(890)$ & $59.0 \%(135)$ & $12.8 \%(41,113)$ & $22.6 \%(23,857)$ & $13.7 \%(12,106)$ & $12.9 \%(796)$ \\
\hline $\begin{array}{l}\text { Any aggressive } \\
\text { behavior }\end{array}$ & $20.9 \%(21,887)$ & $46.9 \%(3598)$ & $26.7 \%(435)$ & $25.3 \%(58)$ & $3.3 \%(10,669)$ & $26.8 \%(28,198)$ & $5.5 \%(4906)$ & $4.2 \%(256)$ \\
\hline \multicolumn{9}{|l|}{ Psychotropic drug use } \\
\hline Antipsychotics* & - & - & - & - & $5.6 \%(17,875)$ & $22.5 \%(23,737)$ & $7.9 \%(7027)$ & $6.9 \%(423)$ \\
\hline Antidepressants* & - & - & - & - & $19.9 \%(63,839)$ & $28.4 \%(29,891)$ & $26.4 \%(23,390)$ & $37.3 \%(2296)$ \\
\hline Anxiolytics* & - & - & - & - & $17.4 \%(55,881)$ & $14.8 \%(15,636)$ & $17.9 \%(15,897)$ & $22.4 \%(1378)$ \\
\hline Sedatives* & - & - & - & - & $14.3 \%(45,837)$ & $11.8 \%(12,465)$ & $14.8 \%(13,075)$ & $16.5 \%(1016)$ \\
\hline $\begin{array}{l}\text { Social worker or } \\
\text { psychologist contact } \dagger\end{array}$ & $54.4 \%(56,958)$ & $59.4 \%(4556)$ & $57.0 \%(927)$ & $55.9 \%(128)$ & $1.6 \%(5044)$ & $1.2 \%(1263)$ & $1.9 \%(1680)$ & $4.0 \%(244)$ \\
\hline \multirow[t]{3}{*}{ Physical restraint use: } & $4.9 \%(5095)$ & $24.1 \%(1851)$ & $7.8 \%(127)$ & $6.6 \%(15)$ & $0.2 \%(706)$ & $1.0 \%(1101)$ & $0.9 \%(783)$ & $1.6 \%(99)$ \\
\hline & \multicolumn{4}{|c|}{ Nursing home } & \multicolumn{4}{|c|}{ Complex Continuing Care } \\
\hline & $\begin{array}{c}\text { Non- } \\
\text { neurological } \\
\text { conditions }\end{array}$ & ADRD & $\begin{array}{l}\text { Other neurolo- } \\
\text { gical } \\
\text { conditions }\end{array}$ & MS & $\begin{array}{c}\text { Non- } \\
\text { neurological } \\
\text { conditions }\end{array}$ & ADRD & $\begin{array}{l}\text { Other neurolo- } \\
\text { gical } \\
\text { conditions }\end{array}$ & MS \\
\hline $\mathbf{n}$ & 51,000 & 107,381 & 29,619 & 2430 & 95,338 & 40,519 & 43,749 & 2428 \\
\hline \multicolumn{9}{|l|}{ DRS } \\
\hline 0 & $42.6 \%(21,694)$ & $31.3 \%(33,508)$ & $38.6 \%(11,397)$ & $39.7 \%(962)$ & $50.7 \%(47,879)$ & $37.6 \%(15,051)$ & $47.7 \%(20,438)$ & $47.9 \%(1152)$ \\
\hline $1-2$ & $29.5 \%(15,029)$ & $36.0 \%(38,576)$ & $33.1 \%$ (9748) & $31.4 \%(762)$ & $28.6 \%(27,018)$ & $31.8 \%(12,753)$ & $30.4 \%(13,002)$ & $27.5 \%(662)$ \\
\hline $3+$ & $27.9 \%(14,177)$ & $32.7 \%(34,979)$ & $28.3 \%(8349)$ & $28.9 \%(701)$ & $20.8 \%(19,628)$ & $30.6 \%(12,256)$ & $21.9 \%(9372)$ & $24.6 \%(591)$ \\
\hline Anxiety symptoms & $34.3 \%(17,511)$ & $30.5 \%(32,692)$ & $32.2 \%(9512)$ & $33.4 \%(811)$ & $23.4 \%(22,337)$ & $31.7 \%(12,837)$ & $22.1 \%(9674)$ & $25.7 \%(625)$ \\
\hline $\begin{array}{l}\text { Any aggressive } \\
\text { behavior }\end{array}$ & $27.1 \%(13,799)$ & $54.2 \%(58,214)$ & $32.0 \%(9476)$ & $28.7 \%(696)$ & $20.3 \%(19,332)$ & $46.7 \%(18,927)$ & $26.6 \%(11,657)$ & $21.7 \%(528)$ \\
\hline \multicolumn{9}{|l|}{ Psychotropic drug use } \\
\hline Antipsychotics* & $20.2 \%(10,322)$ & $41.4 \%(44,453)$ & $21.6 \%(6401)$ & $16.0 \%(388)$ & $14.6 \%(13,938)$ & $36.2 \%(14,655)$ & $14.0 \%(6140)$ & $10.1 \%(245)$ \\
\hline Antidepressants* & $41.0 \%(20,903)$ & $47.1 \%(50,523)$ & $47.3 \%(14,019)$ & $52.9 \%(1286)$ & $25.3 \%(24,157)$ & $31.3 \%(12,672)$ & $30.1 \%(13,154)$ & $37.6 \%$ (914) \\
\hline Anxiolytics* & $19.6 \%(10,021)$ & $14.8 \%(15,909)$ & $17.9 \%(5309)$ & $21.3 \%(518)$ & $34.6 \%(32,994)$ & $29.4 \%(11,894)$ & $27.5 \%(12,014)$ & $30.6 \%(743)$ \\
\hline Sedatives* & $12.5 \%(6369)$ & $8.0 \%(8560)$ & $11.8 \%(3489)$ & $12.8 \%(312)$ & $15.7 \%(14,987)$ & $13.8 \%(5594)$ & $13.4 \%$ (5834) & $13.8 \%(335)$ \\
\hline $\begin{array}{l}\text { Social worker or } \\
\text { psychologist contact } \dagger\end{array}$ & $1.4 \%(725)$ & $1.2 \%(1290)$ & $1.4 \%(418)$ & $1.9 \%(47)$ & $11.7 \%(11,200)$ & $13.0 \%(5251)$ & $10.1 \%$ (4416) & $10.5 \%(256)$ \\
\hline Physical restraint use & $8.4 \%(4287)$ & $25.1 \%(26,921)$ & $17.7 \%(5245)$ & $26.5 \%(644)$ & $9.2 \%(8764)$ & $29.3 \%(11,883)$ & $21.2 \%$ (9293) & $25.3 \%(615)$ \\
\hline
\end{tabular}

Unless otherwise noted, the chi-square p values for group comparisons performed within and across settings are less than 0.0001 .

DRS $=$ Depression Rating Scale

*Items not available on RAI-MH assessment.

$\dagger$ At least one 15-minute session in last 7 days; social worker in $\mathrm{MH} / \mathrm{HC}$, psychologist in $\mathrm{MH} / \mathrm{NH} / \mathrm{CCC}$.

$\ddagger$ Restraint use in the past 7 days in NH/CCC; restraint use in the past 3 days in $\mathrm{MH} / \mathrm{HC}$.

MS-specific instruments commonly used in clinical settings, such as the Expanded Disability Status Scale, ${ }^{40}$ focus primarily on the assessment of functional and cognitive impairment. These are included in interRAI assessments, in addition to numerous psychosocial, medical, and service use variables not considered by the Expanded Disability Status Scale. The assessment and management of these conditions has been identified as an important quality indicator in the delivery of care to persons with MS. ${ }^{41}$

This study raises questions of the adequacy of psychosocial care outside of mental health care settings. It has been reported that 
nearly $40 \%$ of staff in Ontario CCC hospitals do not believe that they have the skills to address the mental health needs of patients. ${ }^{42}$ Although psychotropic drug use was high among persons with MS, psychological therapy was rarely provided in home care, nursing home, and CCC settings. Despite evidence that psychological therapy is effective in treating depression among persons with $\mathrm{MS},{ }^{43}$ depressed persons with MS do not receive more psychological therapy than those without depression. ${ }^{5}$ There may also be reason to question the capacity of mental health facilities to attend to the medical needs of persons with MS. Compared with individuals without neurological conditions, which account for $92 \%$ of psychiatric inpatients, persons with MS experience greater impairment in ADLs, incontinence, swallowing, and mobility. Recognizing the complex needs of persons with MS at various points along the continuum of care suggests that there is value in the use of comprehensive clinical assessments to guide care planning activities.

The results also demonstrate that there is considerable heterogeneity in the characteristics of persons with MS across care settings. Compared with those receiving home care, persons with MS in nursing homes and CCC hospitals were older and experienced greater physical and cognitive impairment. Given that MS is a progressive neurological condition, this variation is to be expected. In the general population, persons with MS had difficulties in similar domains such as ambulation, cognition, and pain. ${ }^{44}$ Similar to the clinical profile of persons with MS in home care in this study, persons with MS in the general population report severe disability. ${ }^{44}$ Given that MS affects numerous domains of health and wellbeing, comparisons of persons with MS between settings, jurisdictions, or countries should take into account the types of clinical covariates included in interRAI assessments.

Within care settings, the clinical profiles of persons with MS are distinct from individuals with other neurological and nonneurological conditions. Persons with MS in this study exceeded the level of functional impairment of peer groups in nursing home and CCC care settings; however, they are also a substantially younger patient population. Interviews with persons with MS in residential care settings suggest that they may find it difficult to interact with other residents with more severe cognitive impairment. ${ }^{45}$ This presents a unique challenge in the delivery of person-centered care that is aligned with the individual strengths, preferences, and needs of minority patient populations in residential care settings. Organizational commitment to personcentered care may not be sufficient to ensure that the social needs of persons with MS are addressed given care providers' orientation toward practice using a medical paradigm. ${ }^{46}$ Future research should aim to evaluate alternative models of care that promote quality of life among all residents, despite the inherent heterogeneity of nursing home residents.

\section{Strengths and Limitations}

The widespread implementation of interRAI instruments across the Canadian continuum of care provides population-level assessment data for persons with MS in several care settings and provinces. This creates a unique opportunity to conduct the largest study to date of persons with MS across the continuum of care in Canada. Using the interRAI suite of validated instruments enables cross-setting comparisons to be made of the clinical profile of persons with MS across four distinct care settings. Future work may take advantage of longitudinal nature of interRAI assessments to conduct analyses of the clinical trajectories of change in this population.

Unlike the new suite of interRAI assessments, the previousgeneration assessments that were used in this study do not differentiate primary and secondary diagnoses. Thus, persons with MS who were included in this sample who have comorbid conditions may have clinical characteristics that are the results of MS. Although this might be seen as a limitation of using secondary data, it also provides a true representation of persons with MS receiving care in the respective care settings where comorbid conditions are common. ${ }^{47}$ Comorbid conditions in this study were not differentiated because the assessments used in various settings contain different diagnoses lists. Also, despite validation of the diagnoses items used for case ascertainment in this study, ${ }^{25-27}$ it is possible that some individuals with an MS diagnosis may not be identified using these sources clinical health information. Finally, the interRAI assessments do not differentiate between subtypes of MS in their pick lists, and it is uncommon for additional information to be added on subtypes within the open-ended ICD diagnostic codes.

\section{Conclusion}

Persons with MS represent a small proportion of patients in each care setting across the continuum of care; however, the prevalence of MS in these community-, institutional-, and hospitalbased care settings is high compared to in the general population. Despite considerable individual variability in MS symptomatology, through a comparison of interRAI assessment data for persons with MS in mental health, home care, nursing home, and CCC care settings, several setting-specific clinical profiles for persons with MS have emerged. Given the progressive nature of disability that is experienced by persons with MS, it is likely that over time persons with MS will receive care in one or more of the care settings that were included in this study's analysis. The interRAI family of assessment instruments provides a valuable data source that can help to understand the characteristics of persons with MS across the continuum of care and to identify areas where care can be improved.

\section{ACKNOWLEDgMenTs AND Funding}

This study is part of the National Population Health Study of Neurological Conditions. We wish to acknowledge the membership of the Neurological Health Charities of Canada and the Public Health Agency of Canada for their contribution to the success of this initiative.

Funding for the study was provided by the Public Health Agency of Canada, Project \#6271-15-2010/3970773. The opinions expressed in this publication are those of the authors/ researchers, and do not necessarily reflect the official views of the Public Health Agency of Canada. RAM is funded in part by the Waugh Family Chair in Multiple Sclerosis. SBP is a Senior Health Scholar with Alberta Innovates, Health Solutions.

\section{Disclosures}

RAM receives research funding from: Canadian Institutes of Health Research, Public Health Agency of Canada, Manitoba Health Research Council, Health Sciences Centre Foundation, Multiple Sclerosis Society of Canada, Multiple Sclerosis 
Scientific Foundation, Rx \& D Health Research Foundation, Consortium of MS Centers, and Crohn's and Colitis Canada. RAM is the principal investigator for a Sanofi Clinical Trial; no personal compensation is received. JPH is a principal investigator for Public Health Agency/Canada and is a grant recipient. LAT and SBP have nothing to disclose.

\section{REFERENCES}

1. Ewing $\mathrm{C}$, Bernard CC. Insights into the aetiology and pathogenesis of multiple sclerosis. Immuno Cell Biol. 1998;76:47-54.

2. Northrop DE, Frankel D. Assisted living for persons with multiple sclerosis. New York, New York: National Multiple Sclerosis Society; 2010.

3. Northrop DE, Frankel D. Nursing home care for individuals with multiple sclerosis: guidelines and recommendations for quality care. New York, New York: National Multiple Sclerosis Society; 2009.

4. Buchanan RJ. Analyses of the minimum data set: comparisons of nursing home residents with multiple sclerosis to other nursing home residents. Mult Scler. 2002;8:512-22.

5. Buchanan RJ, Wang S, Tai-Seale M, Ju H. Analyses of nursing home residents with multiple sclerosis and depression using the minimum data Set. Mult Scler. 2003;9:171-88.

6. Buchanan RJ, Martin RA, Wang S, Ju H. Analyses of nursing home residents with multiple sclerosis at admission and one year after admission. Mult Scler. 2004;10:74-9.

7. Hirdes JP, Mitchell L, Maxwell CJ, White N. Beyond the 'iron lungs of gerontology': using evidence to shape the future of nursing homes in Canada. Can J Aging. 2011;30:371-90.

8. Hirdes JP. Addressing the health needs of frail elderly people: Ontario's experience with an integrated health information system. Age Ageing. 2006;35:329-31.

9. Canadian Institute of Health Information. Continuing Care Reporting System (CCRS) Metadata. Available at: http://www.cihi.ca.

10. Canadian Institute of Health Information. Ontario Mental Health Reporting System (OMHRS) Metadata. Available at: http://www. cihi.ca.

11. Gray LC, Berg K, Fries BE, et al. Sharing clinical information across care settings: the birth of an integrated assessment system. BMC Health Serv Res. 2009;9:71.

12. Hirdes JP, Ljunggren G, Morris JN, et al. Reliability of the interRAI suite of assessment instruments: a 12-country study of an integrated health information system. BMC Health Serv Res. 2008;8:277.

13. Barnaba RR, Landi FF, Onder GG, Liperoti RR, Gambassi GG. Second and third generation assessment instruments: the birth of standardization in geriatric care. J Gerontol. 2008;63:308-13.

14. Teare GF, Daniel I, Markel F, McKillop I, Pink GH, Rashkovan N. Hospital report 2003: complex continuing care. Joint Initiative of the Ontario Hospital Association and the Government of Ontario, Toronto: Hospital Report Research Collaborative, University of Toronto: Hospital Report Research Collaborative; 2004.

15. Health Quality Ontario. The reality of caring: distress among the caregivers of home care patients. 2016. Available at: http:// www.hqontario.ca/Portals/0/documents/system-performance/realitycaring-report-en.pdf.

16. Hirdes JP, Smith TF, Rabinowitz T, et al. The resident assessment instrument-mental health (RAI-MH): Inter-rater reliability and convergent validity. J Behav Health Serv Res. 2002;29:419-32.

17. Morris JN, Fries BE, Mehr DR, et al. MDS cognitive performance scale. J Gerontol. 1994;49:M174-82.

18. Hartmaier SL, Sloane PD, Guess HA, Koch GG, Mitchell CM, Phillips CD. Validation of the Minimum Data Set Cognitive Performance Scale: agreement with the Mini-Mental State Examination. J Gerontol A Biol Sci Med Sci. 1995;50: M128-33.

19. Jones K, Perlman CM, Hirdes JP, Scott T. Screening cognitive performance with the Resident Assessment Instrument for Mental Health Cognitive Performance Scale. Can J Psychiatry. 2010;55:736-40.
20. Burrows AB, Morris JN, Simon SE, Hirdes JP, Phillips CA. Development of a minimum data set-based depression rating scale for use in nursing homes. Age Ageing. 2000;29:165-72.

21. Morris JN, Fries BE, Morris SA. Scaling ADLs within the MDS. J Gerontol. 1999;54:M546-53.

22. Fries BE, Simon SE, Morris JN, Flodstrom C, Bookstein FL. Pain in U.S. nursing homes: validating a pain scale for the minimum data set. Gerontologist. 2001;41:173-9.

23. Hirdes JP, Frijters DH, Teare GF. The MDS-CHESS scale: a new measure to predict mortality in institutionalized older people. J Am Geriatr Soc. 2003;51:96-100.

24. Hirdes JP, Poss JW, Mitchell L, Korngut L, Heckman G. Use of the interRAI CHESS scale to predict mortality among persons with neurological conditions in three care settings. PLoS ONE. 2014;9: e99066.

25. Foebel AD, Hirdes JP, Heckman GA, Kergoat MJ, Patten S, Marrie R. Diagnostic data for neurological conditions in interRAI assessments in home care, nursing home and mental health care settings: a validity study. BMC Health Serv Res. 2013;13:457.

26. Lix LM, Yan L, Blackburn D, Hu N, Schneider-Lindner V, Teare GF. Validity of the RAI-MDS for ascertaining diabetes and comorbid conditions in long-term care facility residents. BMC Health Serv Res. 2014:14.

27. Danila O, Hirdes JP, Maxwell CJ, et al. Prevalence of neurological conditions across the continuum of care based on interRAI assessments. BMC Health Serv Res. 2014:14.

28. Caesar-Chavannes CR, MacDonald S. Cross-Canada forumNational Population Health Study of Neurological Conditions in Canada. Chronic Dis Inj Can. 2013;33:188-91.

29. Public Health Agency of Canada (PHAC). The National Population Health Study of Neurological Conditions. Available at: http:// www.phac-aspc.gc.ca/cd-mc/nc-mn/ns-en-eng.php.

30. Benjamini Y, Hochberg Y. Controlling the false discovery rate: a practical and powerful approach to multiple testing. J Royal Stat Soc Series B. 1995;57:289-300.

31. Evans C, Beland SG, Kulaga S, et al. Incidence and prevalence of multiple sclerosis in the Americas: a systematic review. Neuroepidemiology. 2013;40:195-210.

32. Kingwell E, Marriott JJ, Jetté N, et al. Incidence and prevalence of multiple sclerosis in Europe: a systematic review. BMC Neurol. 2013:13.

33. Makhani N, Morrow SA, Fisk J, et al. MS incidence and prevalence in Africa, Asia, Australia and New Zealand: a systematic review. Mult Scler Relat Disord. 2014;3:48-60.

34. Kingwell E, Zhu F, Marrie RA, et al. High incidence and increasing prevalence of multiple sclerosis in British Columbia, Canada: findings from over two decades (1991-2010). J Neurol. 2015;262:2352-63.

35. Marrie RA, Yu N, Blanchard J, Leung S, Elliott L. The rising prevalence and changing age distribution of multiple sclerosis in Manitoba. Neurology. 2010;74:465-71.

36. Marrie RA, Fisk JD, Stadnyk KJ, et al. The incidence and prevalence of multiple sclerosis in Nova Scotia, Canada. Can J Neurol Sci. 2013;40:824-31.

37. Hader WJ, Yee IML. Incidence and prevalence of multiple sclerosis in Saskatoon, Saskatchewan. Neurology. 2007;69:1224-9.

38. Beck CA, Metz LM, Svenson LW, Patten SB. Regional variation of multiple sclerosis prevalence in Canada. Mult Scler. 2005; 11:516-9.

39. Marrie RA, Fisk JD, Yu BN, et al. Mental comorbidity and multiple sclerosis: validating administrative data to support populationbased surveillance. BMC Neurol. 2013:13.

40. Kurtzke JF. Rating neurologic impairment in multiple sclerosis an expanded disability status scale (EDSS). Neurology. 1983;33:1444.

41. Cheng EM, Crandall CJ, Bever CT, et al. Quality indicators for multiple sclerosis. Mult Scler J. 2010;16:970-80.

42. Gibson A, Kuluski K, Lyons R. Complex health conditions and mental health training: How prepared is the frontline service provider? Healthcare Manage Forum. 2015;28:16-23.

43. Mohr DC, Boudewyn AC, Goodkin DE, Bostrom A, Epstein L. Comparative outcomes for individual cognitive-behavior therapy, supportive-expressive group psychotherapy, and sertraline for the 
treatment of depression in multiple sclerosis. J Consult Clin Psychol. 2001;69:942-9.

44. Jones CA, Pohar SL, Warren S, Turpin KV, Warren KG. The burden of multiple sclerosis: a community health survey. Health Quality Life Outcomes. 2008;6:1.

45. Riazi A, Bradshaw SA, Playford ED. Quality of life in the care home: a qualitative study of the perspectives of residents with multiple sclerosis. Disabil Rehabil. 2012;34:2095-102.
46. Rissanen L, Ehrlich C, Kendall E, Muenchberger H. Realizing person-centred care in residential care facilities for young adults with complex and chronic disabilities: the understanding, perception and beliefs of workers. Eur J Person Centered Healthcare. 2014;2:190-200.

47. Marrie R, Horwitz R, Cutter G, Tyry T, Campagnolo D, Vollmer T. Comorbidity, socioeconomic status and multiple sclerosis. Mul Scler. 2008;14:1091-8. 